\title{
A new design for a submersible chronographic tethering device to record predation in different habitats
}

\author{
M. D. E. Haywood*, R. C. Pendrey \\ CSIRO Division of Fisheries, PO Box 120, Cleveland, Queensland 4163, Australia
}

\begin{abstract}
We describe a design for a submersible chronographic tethering device which can be used to measure the survival time of small tethered prey. This technique can be used to compare survival in different habitat types. We tested the tethering device using juvenile tiger prawns Penaeus semisulcatus both in the laboratory and field using 3 levels of shoot density of artificial seagrass $\left(0,15\right.$ and 60 shoots $\mathrm{m}^{-2}$ ) Tethering did not prevent burying behaviour in the laboratory. In the field, more prawns were taken from the 0 and 15 shoots $\mathrm{m}^{-2}$ than the 60 shoots $\mathrm{m}^{-2}$ treatment and prawns that were tethered in the 60 shoots $\mathrm{m}^{-2}$ treatment also survived longer than those in the other treatments. This device should prove useful for estimating predation potential for a variety of small key prey among different habitats and seasons
\end{abstract}

KEY WORDS: Tethering · Predation · Penaeid

Natural mortality rates of commercially important species of penaeids may be critical in determining the size of recruitment to the fishery. The main cause of natural mortality of postlarval and juvenile brown shrimp Penaeus aztecus is probably predation by fish (Minello et al. 1989). Traditionally, predation rates on key prey species have been estimated by sampling potential predators and examining their gut contents (e.g. Salini et al. 1990, Brewer et al. 1995). This may not be suitable when the aim of the investigation is to compare predation rates in different habitats. For example, many predatory fish species are highly mobile and their gut contents may contain items caught in more than 1 habitat type. An alternative technique is to exclude predators and compare mortality rates in the presence and absence of predators (e.g. Minello et al. 1989). However this is time consuming and may introduce problems with caging effects.

•E-mail:mick.haywood@qld.ml.csiro.au
Tethering techniques are a better method of comparing predation levels on small prey items in different habitats. Organisms such as blue crabs (Wilson et al. 1990), juvenile lobsters (Barshaw \& Able 1990, Wahle \& Steneck 1992), ophiuroids (Aronson 1989), Dungeness crab (Fernandez et al. 1993), brachyuran and hermit crabs (Heck \& Thoman 1981, Heck \& Wilson 1987). juvenile scallops (Barbeau \& Scheibling 1994), mangrove leaves (Robertson 1986) and seaweed (Hay 1984) have been used in tethering experiments. In most cases a tether (usually monofilament line) is attached to the prey animal and the other end is staked to the substrate, in the habitat of interest. The prey animals are left for a period, usually about a day, before being recovered. The numbers of prey surviving in each habitat are then compared.

A major problem with this general technique is that the duration of the experiment is critical: if the experiment is too short, none of the prey will be taken; if it is too long, all the prey from all treatments will be taken. Minello (1993) developed a device for tethering penaeid prawns that recorded the time at which each tethered prawn was taken, so the tethered prawns had to be left out only long enough for most of them to be eaten. More information per animal was also recorded because 'survival time' was measured, rather than just the presence or loss of prawns being noted.

Minello (1993) used his chronographic tethering device in Galveston Bay, Texas (USA). As the bay has only a small tidal range, his non-submersible device could be suspended above the surface of the water with the tethers passing through the water column. We needed to develop a submersible tethering device since we wanted to conduct tethering experiments in an area with a tidal range of up to $3 \mathrm{~m}$. Although we could have used Minello's (1993) design, strong tidal currents and floating debris in the water column may have pulled on the tethers, triggering the watches. 
In laboratory trials, a prototype tethering device that used monofilament fishing line and relied on the mechanical pull of the predator to trigger the timer proved to be species-specific with regard to its reliability. For a sparid Rhabdosagrus sarbra predator the device was $90 \%$ efficient; but for pufferfish Torquigener hamiltoni, the timer was never triggered when prawns were taken. This difference could be explained by the 2 species' different modes of attack: the sparid seized the prawn in its mouth and swam away rapidly, which resulted in a sharp tug on the tether, triggering the timer; in contrast, pufferfish approached the prawn slowly and bit it cleanly into several pieces before eating it, without triggering the timer.

This manuscript describes the design of a submersible chronographic tethering device which is triggered by the release of hydrostatic pressure and is independent of the feeding mode of the predator. We also give details of laboratory testing and a field trial in which the device was used to demonstrate survival rates of juvenile prawns in different shoot densities of artificial seagrass.

Methods. Chronographic tethering device: Our chronographic tethering device consisted of a digital watch fixed to the side of a $5 \mathrm{ml}$ disposable syringe (Fig. 1). Each prawn was tethered to a length of fine silicon tubing that was attached to the syringe. When a tethered prawn was eaten, the watch started timing. By recording the time the device was recovered and the time registered by the watch, we were able to calculate survival time for each tethered prawn.

Tethers: The tethers were made from $25 \mathrm{~cm}$ lengths of Dow Corning medical grade silicon tubing $(0.3 \mathrm{~mm}$ internal diameter, ID; $0.64 \mathrm{~mm}$ outer diameter, OD). A small drop of silicon sealer $15 \mathrm{~mm}$ from the end of the tether that was attached to the prawn helped stop the end of the tether from slipping through the noose around the prawn (Fig. 2). The other end was inserted through a $1 \mathrm{ml}$ plastic disposable pipette tip which was then connected to the $3 \mathrm{~mm}$ ID silicon tubing attached to the syringe.

Timers: The chronographic timers were constructed from cheap, waterproof, digital watches that started timing from 12:00 $\mathrm{h}$ when the power was restored, after the prawn had been eaten. The watch's power circuit was interrupted with a magnetic reed switch. A reed switch is a miniature device used to switch electrical currents. It consists of 2 thin strips of metal sealed within a glass vial; the metal strips are aligned so that their tips overlap and they make contact when the device is placed within a magnetic field. One of the watch's battery contacts was removed and replaced with a reed switch. This meant the watch was turned off until a magnet was placed close to the watch.

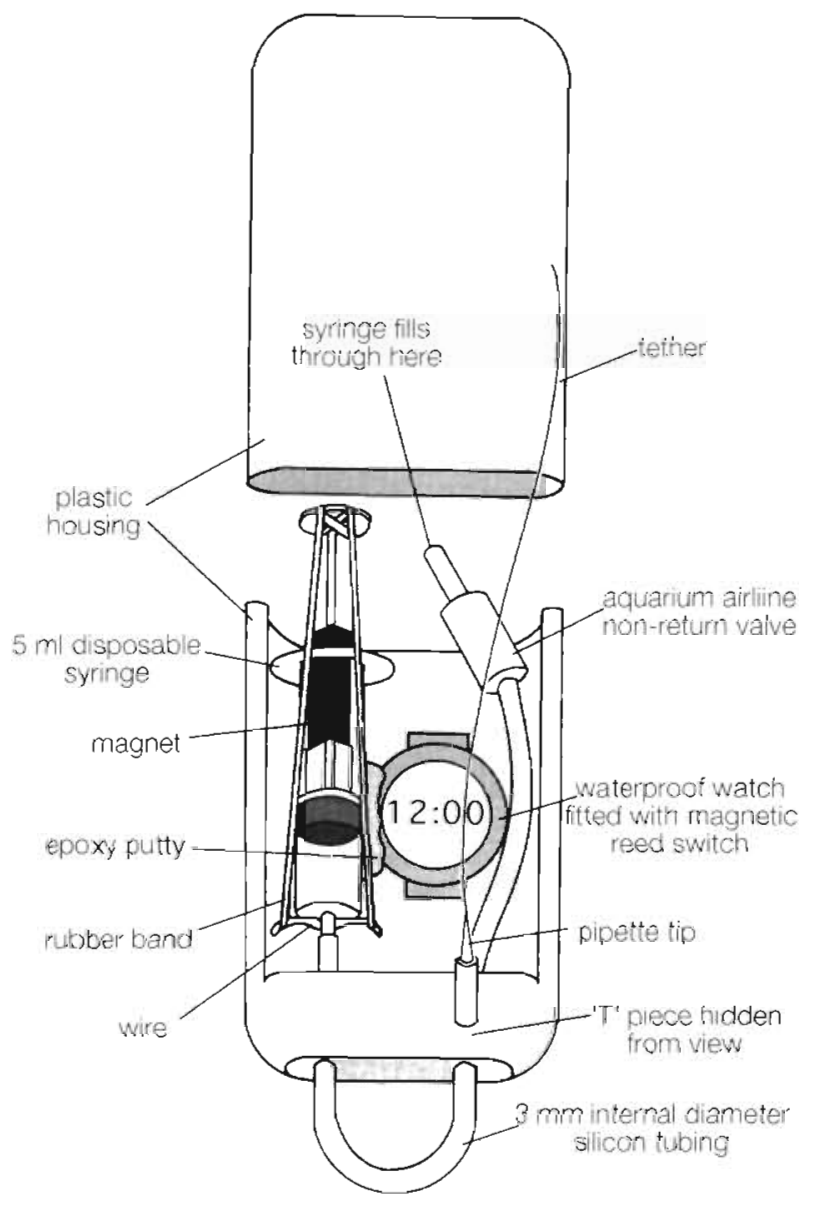

Fig. 1. Schematic detailing of the components of the tethering chronograph used to measure the survival time of Penaeus semisulcatus tethered among different shoot densities of artifical seagrass. Watch in this figure is shown as being 'on' for clarity, although the syringe plunger is withdrawn. Plastic housing cover is withdrawn to show the chronograph components

The watches were fixed with epoxy putty to the side of a $5 \mathrm{ml}$ disposable syringe. A piece $(2 \mathrm{~cm}$ long) was cut from the shaft of the syringe plunger to allow a magnet to be mounted in its place (Fig. 1). When the plunger of the syringe was depressed, the magnet was brought within range of the reed switch, closing the switch and thus restoring power to the watch; when the plunger was raised $2 \mathrm{~cm}$, the watch was turned off.

When the power was restored the watches displayed in $12 \mathrm{~h}$ notation. Display of the a.m./p.m. indicator required a button to be toggled, but this proved to be a source of water leakage and had to be sealed over with epoxy resin. This meant that if the watches were deployed for more than $12 \mathrm{~h}$, it would be impossible to determine whether the time displayed upon recovery represented the time since the prawn was eaten, or $12 \mathrm{~h}$ plus the time since the prawn was eaten.

A piece of $1.5 \mathrm{~mm}$ diameter wire was bent to fit around the end of the syringe and held in place with 
epoxy putty (Fig. 1). Two rubber bands ( $75 \mathrm{~mm}$ long, $6 \mathrm{~mm}$ wide) were stretched from the wire to the plunger of the syringe. These provided sufficient force to depress the syringe plunger One end of a piece of $3 \mathrm{~mm}$ ID silicon tubing was fixed to the end of the syringe and the other end of the tubing was fastened to a ' $T$ '-piece. The tether was connected to one arm of the ' $T$ '-piece. The device was loaded through the other arm of the ' $\mathrm{T}$ ' piece; an airline non-return valve was placed in this line to prevent the pressure releasing after the device was loaded. The whole assembly was then mounted in a small plastic housing $(130 \times 75 \times$ $31 \mathrm{~mm}$ ); we used empty room deodoriser canisters.

Tethering: Small plastic rings $(2 \mathrm{~mm}$ ID) were made by cutting $1 \mathrm{~mm}$ thick slices through ball point ink cartridges. These were mounted on a small piece of epoxy putty to give them a surface suitable for gluing to the prawn's carapace. Nooses were made by tying a slip-knot in $2 \mathrm{~kg}$ test strength fishing line.

Tethering was done in 2 stages: first a plastic ring was fixed to the right-hand side of the prawn's carapace with a drop of cyanoacrylate glue (Supa Glue), and then a noose was fitted around the prawn immediately behind the carapace. The tether was passed through the noose and plastic ring. The noose was then tightened and a drop of Supa Glue applied to the noose slip-knot and another to the tether where it passed under the noose. The end of the tether was then doubled back on itself, kinked, and then passed back through the plastic ring twice. This effectively sealed the end of the tubing so that the syringe could not discharge. During pilot studies 10 prawns tethered in this way lived for 4 to $5 \mathrm{~d}$.

When a prawn was eaten, fish either bit through the tether or dislodged it from the plastic ring, releasing the kinks. This released the water pressure, allowing the syringe plunger to move the magnet alongside the reed switch, restoring power to the watch. Thus the triggering mechanism did not rely on the predator tugging on the tether.

Apparatus testing: Laboratory observations: Juvenile Penaeus semisulcatus were used to test the apparatus both in the laboratory and in the field. They were caught using a small beam trawl towed from a $5 \mathrm{~m}$ dinghy over a bed of the seagrass Enhalus acoroides in the Embley River near Weipa, northeastern Gulf of Carpentaria, Australia (see Haywood et al. 1995 for a description of the site and catching methods). Field testing was done in the Embley River, while behavioural observations were done at the CSIRO Marine Laboratories in Brisbane.

The reliability of the tethering method and the timing devices were tested first in $2 \mathrm{~m}$ diameter fibreglass tanks in the laboratory. This work was carried out between September and November 1994. At about 16:00 h each day, juvenile Penaeus semisulcatus were tethered and attached to a timer. To study their behaviour, they were filmed on video overnight under red light.

Field trials: The device was field tested in October 1994. Prawns were maintained in small (50 l) aquaria at the CSIRO field laboratory in Weipa and then tethered and deployed in the field among $1 \mathrm{~m}^{2}$ plots of artificial seagrass. Artificial seagrass was used because different levels of a particular treatment (shoot density) could be placed within $3 \mathrm{~m}$ of each other, to expose them to the same suite of predators. The seagrass was designed to simulate Enhalus acoroides. Its shoots were composed of 4 'leaves' $(1.5 \mathrm{~cm}$ wide $\times 40 \mathrm{~cm}$ high) attached to $1 \mathrm{~m}^{2}$ sheets of galvanised weld-mesh. The gaps in the mesh $(70 \mathrm{~mm}$ squares) were sufficient to 
allow the prawns to bury. The 'leaves' were made from green plastic sheeting (Fabricon ss, Rheem Australia Ltd), which floated erect in seawater, simulating living blades of $E$. acoroides. The seagrass plots had 0,15 or 60 shoots $\mathrm{m}^{-2}$ attached to the weld-mesh with plastic cable ties. The shoot density for natural $E$. acoroides ranged between 71 and 83 shoots $\mathrm{m}^{-2}$ at this site over the years 1989-92 (M. D. E. Haywood unpubl. data).

Site: All experiments were conducted on a bare area $(\sim 10 \times 10 \mathrm{~m})$ within a large (>3 ha) seagrass bed (predominantly composed of Enhalus acoroides). The experimental site, which was in the intertidal zone, was exposed at low tide for $1 \mathrm{~h}$ during the first night (05:00 to $06: 00 \mathrm{~h}$ ) and $0.5 \mathrm{~h}$ during the second night (05:30 to $06: 00 \mathrm{~h})$ of the experiment and for $2 \mathrm{~h}$ $(00: 00$ to $02: 00 \mathrm{~h})$ on the last night of the experiment. As juvenile Penaeus semisulcatus remain in the seagrass bed and bury in the substrate when an area is exposed (Vance et al. 1994), the only effect of the exposure was likely to be a reduction in the amount of time the prawns were available to predators.

Deployment: Juvenile Penaeus semisulcatus (8 to $14 \mathrm{~mm}$ carapace length, CL) were tethered in the laboratory at Weipa on the day of the experiment and kept individually in $250 \mathrm{ml}$ plastic jars to prevent entangling of their tethers. The watches were turned off by pressurising the syringes with about $4 \mathrm{ml}$ of deionised water, using another syringe. A spring-clip was fastened to the loop of silicon tubing protruding from the device housing (Fig. 1), to prevent the water escaping from the syringe.

The tethered prawns were deployed between 17:00 and 19:00 h each evening and recovered within $12 \mathrm{~h}$. Either 24 or 36 tethered Penaeus semisulcatus (4 per plot) were deployed on the artificial seagrass plots each evening. The plots were arranged in 2 or 3 rows with 1 of each seagrass density treatment (i.e. 0,15 , and 60 shoots $\mathrm{m}^{-2}$ ) in each row. The order of the treatments within each row was chosen using a table of random numbers. Any seagrass plots not recovered within $12 \mathrm{~h}$ were excluded from the analyses.

Temperatures recorded at the time of deployment ranged from 28.0 to $28.9^{\circ} \mathrm{C}$.

The tethering devices were attached with Velcro ${ }^{\mathrm{M}}$ straps to each artificial seagrass plot. A tethered prawn was attached to each tethering device and the plot was lowered carefully to the bottom. A small polystyrene buoy attached to each plot ensured their recovery.

Data analysis: We recorded when the tethering devices were deployed and recovered, whether the prawns had been eaten, and, if so, the time displayed by the watches. We could then calculate the survival time for each prawn. Some prawns survived for the duration of the experiment (censored observations). We used survival analysis techniques which use both the survival times of animals which did not survive the duration of the experiment as well as the censored observations (Armitage \& Berry 1971, SAS 1990). PROC LIFETEST is a program that generates survival distribution curves for each treatment. Each curve illustrates the relative rate of survival over time. The survival curves were then compared by 2 rank tests (log rank and Wilcoxon tests; Kalbfleisch \& Prentice 1980), which determine whether 2 or more samples could be described by the same survival function.

Results. Laboratory observations: Penaeus semisulcatus normally bury in the substrate during the day, and tethering did not appear to interfere with this behaviour. None of the prawns escaped from the tether during the observation period, although 1 moulted and died. Temperatures in the experimental aquaria ranged from 18.5 to $25.0^{\circ} \mathrm{C}$.

To check that the watches were recording the correct time after predation, we ran 20 laboratory trials. For each trial, a single tethered Penaeus semisulcatus was kept in an aquarium for periods of 12 to $14 \mathrm{~h}$ after which a pufferfish Torquigener hamiltoni was introduced to the aquarium. All prawns were consumed by the fish within several minutes of the fish being introduced to the aquarium. We recorded the time at which each prawn was eaten, then recovered the tethering devices and read the watch times at periods ranging between 5 min and $4 \mathrm{~h}$.

Eighteen of the 20 watches were triggered within $30 \mathrm{~s}$ of the prawns being eaten by the fish. In the other 2 watches the plunger jammed in the syringe; this sometimes happened after the syringe had been used several times. This was remedied by washing the syringe plunger in methylated spirits and applying a water-based lubricant (KY jelly, Johnson \& Johnson) (petroleum-based lubricant was not used, to avoid blocking the fine tether tubing).

Field trials: The proportion of tethered prawns remaining after $12 \mathrm{~h}$ ranged from $7.1 \%$ for 0 shoots $\mathrm{m}^{-2}$ to $46.9 \%$ for prawns tethered in the 60 shoots $\mathrm{m}^{-2}$ seagrass plots, while the mean survival time ranged from $294 \pm 59.7$ to $583 \pm 48.7$ min (mean $\pm \mathrm{SE}$ ) (Table 1 ). The remaining prawns were alive and did not appear to have suffered from the tethering. Eighteen of the 92 tethering devices deployed in the field did not trigger when the prawn was eaten because the syringe plungers stuck.

Both the log-rank $\left(\chi^{2}=12.37\right.$, df $\left.=2, p=0.002\right)$ and the Wilcoxon $\left(\chi^{2}=14.29\right.$, df $\left.=2, p=0.0008\right)$ tests were highly significant, indicating different patterns of survival in the different seagrass densities. The shape of the survival functions generated for the different seagrass densities showed a similar pattern in all treatments (Fig. 3). Survival rates declined rapidly twice during the 12 h that the tethered prawns were de- 
Table 1. Penaeus semisulcatus. Numbers of prawns surviving after being tethered for $12 \mathrm{~h}$ on artificial seagrass plots in an intertidal seagrass bed. Only prawns that were eaten were included in the calculation of mean survival time. SE: standard error of mean survival time

\begin{tabular}{|cccccc|}
\hline $\begin{array}{c}\text { Seagrass density } \\
\text { (shoots } \mathrm{m}^{-2} \text { ) }\end{array}$ & $\begin{array}{c}\text { Total number of } \\
\text { tethered prawns }\end{array}$ & $\begin{array}{c}\text { Number of } \\
\text { prawns eaten }\end{array}$ & $\begin{array}{c}\text { Number of } \\
\text { prawns surviving }\end{array}$ & $\begin{array}{c}\text { \% surviving } \\
\text { Mean survival } \\
\text { time (min) }\end{array}$ \\
\hline 0 & 28 & 26 & 2 & 7.1 & 294 \\
15 & 32 & 25 & 7 & 21.9 & 365 \\
60 & 32 & 17 & 15 & 46.9 & 593 \\
\hline
\end{tabular}

ployed. The first decline came immediately after deployment and lasted for about 150 min (Fig. 3). For the next 225 to $270 \mathrm{~min}$, the rate was relatively constant, but then decreased steadily until the end of the experiment. Since the tethered prawns were all deployed between 17:00 and 19:00 h, the first major decline occurred at dusk. The survival rate then levelled off for about $6.5 \mathrm{~h}$; the next drop was between 02:00 and 04:00 $\mathrm{h}$, until the tethering devices were recovered after dawn (about 05:00 h).

Discussion. Tethering studies have been used to assess predation or grazing rates on organisms ranging from seaweeds (Hay et al. 1988) to juvenile lobsters (Wahle \& Steneck 1992). Until the introduction of the chronographic tethering device by Minello (1993), information collected from these studies was limited to presence/absence data, the duration of the experiment was critical (see above) or the prey had to be checked repeatedly during the experiment.

We developed a new chronographic tethering device based on Minello's (1993) original design. Our timer is submersible and so can be used in subtidal areas and in intertidal areas with a large tidal exchange. Its hydrostatic triggering mechanism is independent of the predator's feeding mode and works even if the tether becomes entangled.

These field tests showed there were differences between treatments in the mean survival time and the numbers of surviving prawns. The value of the timing device was demonstrated in subsequent experiments where there were no survivors in any treatment (M. D. E. Haywood, N. R. Loneragan \& F. J. Mansen unpubl. data). Other studies have sampled tethered prey repeatedly throughout the experiment in order to gain measures of survival time (e.g. Aronson 1987, Barbeau \& Schiebling 1994). However, in our case this was impractical, since the experiments were done at night in turbid water that was up to $3 \mathrm{~m}$ deep at high tide. Also, repeatedly visiting the tethered prey would disturb predators in the area, possibly affecting predation rates. All these factors make the use of timing devices more attractive for field studies.

While tethering techniques cannot be used to determine absolute rates of predation, they are useful for assessing relative predation rates in different sites or seasons. The validity of tethering experiments has recently been debated (e.g. Peterson \& Black 1994, Aronson \& Heck 1995). The argument in support of tethering is that the artefact due to tethering will be constant across all treatments because all the experimental animals are tethered; the counter-argument is that tethering may induce non-additive artefacts that will vary with the treatment (Peterson \& Black 1994).

It is possible, for example, that the tethers are more likely to entangle in dense seagrass, making tethered prawns more vulnerable to predators than those tethered in sparse seagrass. If this were so, we would expect lower survival in the higher shoot densities, but the results do not support this hypothesis. Similarly, other studies have found reduced mortality of prey 
tethered in aquatic vegetation compared with bare areas, notwithstanding the possibility of entanglement (see references cited in Aronson \& Heck 1995). Nevertheless, concerns over artefacts in tethering experiments are valid and we are presently examining the effect of tethering on prawn behaviour and predator success rates.

Acknowledgements. We thank $N$. Loneragan for help in the field. T J. Minello, B. Hill, N. Loneragan, V. Mawson, T Skews and 4 anonymous reviewers made constructive comments on the draft manuscript and Y.-G. Wang provided statistical advice and introduced us to survival analysis

\section{LITERATURE CITED}

Armitage P, Berry G (1971) Statistical methods in medical research. Blackwell, Oxford

Aronson RB (1987) Predation on fossil and recent ophiuroids. Paleobiology 13(2):187-192

Aronson RB (1989) Brittlestar beds: low-predation anachronisms in the British Isles. Ecology 70(4):856-865

Aronson RB, Heck KL Jr (1995) Tethering experiments and hypothesis testing in ecology. Mar Ecol Prog Ser 121: 307-309

Barbeau MA, Scheibling RE (1994) Procedural effects of prey tethering experiments: predation of juvenile scallops by crabs and sea stars. Mar Ecol Prog Ser 111:305-310

Barshaw D, Able KW (1990) Tethering as a technique for assessing predation rates in different habitats: an evaluation using juvenile lobsters Homarus americanus. Fish Bull US 88:415-417

Brewer DT, Blaber SJM, Salini JP, Farmer MJ (1995) Feeding ecology of predatory fishes from Groote Eylandt in the Gulf of Carpentaria, Australia, with special reference to predation on penaeict prawns. Estuar Coast Shelf Sci 40: $577-600$

Fernandez M. Iribane O. Armstrong D (1993) Habitat selection by young-of-the-year Dungeness crab Cancer magister and predation risk in intertidal habitats. Mar Ecol Prog Ser 92:171-177

Hay ME (1984) Patterns of fish and urchin grazing on Carrbbean coral reefs: are previous results typical? Ecology 65(2):446-454

Hay ME, Duffy JE, Fenical W, Gustafson K (1988) Chemical

This note was submitted to the editor defence in the seaweed Dictyopteris delucatula: differential effects against reef fishes and amphipods. Mar Ecol Prog Ser 48:185-192

Haywood MDE, Vance DJ, Loneragan NR (1995) Seagrass and algal beds as nursery habitats for tiger prawns (Penaeus semisulcatus and $P$. esculentus) in a tropical Australian estuary. Mar Biol 122(2):213-223

Heck KL Jr, Thoman TA (1981) Experiments on predator-prey interactions in vegetated aquatic habitats. J Exp Mar Bıl Ecol 53:125-134

Heck KL Jr, Wilson KA (1987) Predation rates on decapod crustaceans in latitudinally separated seagrass communities: a study of spatial and temporal variation using tethering techniques. J Exp Mar Biol Ecol 107:87-100

Kalbfleisch JD, Prentice RL (1980) The statistical analysis of failure time data. John Wiley \& Sons, New York

Minello TJ (1993) Chronographic tethering: a technique for measuring prey survival time and testing predation pressure in aquatic habitats. Mar Ecol Prog Ser 101:99-104

Minello TJ, Zimmerman RJ, Martinez EX (1989) Mortality of young brown shrimp Penaeus aztecus in estuarine nurseries. Trans Am Fish Soc 118:693-708

Peterson CH, Black R (1994) An experimentalist's challenge: when artifacts of intervention interact with treatments Mar Ecol Prog Ser 111:289-297

Robertson AI (1986) Leaf-burying crabs: their influence on energy flow and export from mixed mangrove forests (Rhizophora spp.) in northeastern Australia. J Exp Mar Biol Ecol 102:237-248

Salini JP, Blaber SJM, Brewer DT (1990) Diets of piscivorous fishes in a tropical Australian estuary, with special reference to predation on penaeid prawns. Mar Biol 105:363-374

SAS (1990) SAS/STAT user's guide, Version 6, 4th edn, Vol 2 SAS Institute, Cary, NC

Vance DJ, Heales DS, Loneragan NR (1994) Seasonal, diel and tidal variation in beam-trawl catches of juvenile grooved tiger prawns, Penaeus semisulcatus (Decapoda. Penaeidae), in the Embley River, north-eastern Gulf of Carpentaria, Australia. Aust J Mar Freshwat Res 45:35-42

Wahle RA, Steneck RS (1992) Habitat restrictions in early benthic life: experiments on habitat selection and in situ predation with the American lobster. J Exp Mar Biol Ecol 157:91-114

Wilson KA, Able KW, Heck KL Jr (1990) Predation rates on juvenile blue crabs in estuarine nursery habitats: evidence for the importance of macroalgae (Ulva lactuca). Mar Ecol Prog Ser 58:243-251

Manuscript furst received: May 22, 1996

Revised version accepted: August 23, 1996 